\author{
REVISTA DE SOCIOLOGÍA \\ $\mathrm{N}^{\circ} 16-2002$ \\ Facultad de Ciencias Sociales - Universidad de Chile
}

(p. $59-79)$

\title{
Cuestiones Cruciales En El Presente Político
}

\author{
Angel Flisfisch F.
}

\section{Introducción}

Para bien o para mal, la práctica de la reflexión y el análisis sobre los hechos y procesos societales y los productos de esa actividad siempre han estado dotados de una relevancia política. Obviamente, el "siempre" es relativo: la referencia es aproximadamente a los últimos doscientos a doscientos cincuenta años, el período de ya abierto desarrollo de una racionalidad científica moderna que procura comprender la realidad societal en términos seculares y que se asocia a la vez con transformaciones modernizadoras de la economía, la política y la vida social en general.

En alguna instancia organizacional, esos productos intelectuales han sido y son parte importante de la "caja de herramientas" a la que apelan, con fines ciertamente diversos, miembros de las elites políticas para hacerse de insumos utilizables en su accionar.

Como se dijo, los fines a los que sirven esas "herramientas" son diversos. En algunos casos, se trata simplemente de justificar o legitimar decisiones, cursos de acción, políticas o prácticas que han sido previamente determinados por consideraciones ajenas a los productos mismos. No obstante, en otros casos estos productos operan como "conocimientos": se los utiliza de la misma manera que el ingeniero emplea conocimientos provenientes de la física o la química para idear, proyectar y construir un puente: ingeniería económica, social, política, etc. Lo que se encuentra con la mayor frecuencia en el devenir histórico es una fusión de intereses y "conocimientos", y no es tarea fácil separar uno de otro componente. Quizás la sola empresa de procurar separarlos es de por sí ilusoria.

Ciertamente, esa utilización tecnológica de los productos de la sociología, la politología, la antropología y toda la amplia gama de actividades englobadas bajo el rótulo de ciencias sociales es siempre cuestionable desde variadas perspectivas epistemológicas, disciplinarias y metadisplicinarias. En efecto, parte no menor de los esfuerzos de segmentos de los cultores de estas mismas disciplinas reside en relativizar, cuestionar y criticar ese empleo de los productos de las disciplinas como "conocimientos" válidos y aplicables a actividades sobre los procesos societales, desde la premisa que esa utilización es en realidad ideológica y por consiguiente distorsionadora de la objetividad requerida por el esfuerzo cabalmente científico. No obstante esos cuestionamientos, un componente importante de la facticidad societal en cualquier momento reside en ese elevar a un cierto status de "validez científica" los productos en cuestión y en el efectivo empleo que de ellos se hace. 
A la vez, estos productos son interiorizados, de maneras también diversas y a través de elaboraciones igualmente muy distintas, por los sentidos comunes masivos. Cómo aprecian y asocian hoy los llamados públicos masivos fenómenos como el desempeño gubernamental y el curso de la economía se explican no sólo por identificaciones y posicionamientos actitudinales afectivos primarios, o por la conciencia que se tenga de intereses propios que están en juego en la dinámica de esos fenómenos, sino a la vez por lo que se ha llamado "creencias tecnológicas", componentes de subjetividades societales que en una gran mayoría de casos derivan de una recepción y procesamiento de los productos de las llamadas ciencias sociales.

Si bien lo afirmado aspira a una validez general, parece ser particularmente cierto en el caso de la tradición político-cultural que aquí se ha denominado de progresismo. En efecto, desde la tradición europea ilustrada en adelante, los emprendimientos políticos orientados primordialmente por el ideal emancipatorio hecho explícito y argumentado coherentemente por esa tradición y expresiones intelectuales posteriores que de ella derivaron, y que plasmaron prácticamente en hechos históricos como la revolución francesa, los diversos movimientos revolucionarios, particularmente en Europa occidental, del siglo XIX, el surgimiento de organizaciones políticas social demócratas y laboristas a fines de ese siglo y durante el siglo $\mathrm{XX}$ en ese mismo ámbito geopolítico, que se han extendido y globalizado contemporáneamente, han procurado elaborar y legitimar sus acciones, programas o plataformas, estrategias y ciertamente sus políticas cuando han conquistado o compartido gobiernos, fusionando la inteligencia práctica y el obrar políticotáctico cotidianos con análisis y comprensiones de un nivel superior, que han descansado en teorizaciones e investigaciones con aspiración a la cientificidad. Ciertamente, lo anterior es también cierto respecto de los movimientos y organizaciones socialistas revolucionarias y de los desarrollos político-culturales que las ampararon, desarrollos que se acabaron finalmente por englobar de manera genérica bajo el rótulo de marxismo. Lo que permite otorgar un tratamiento diferenciado a los fenómenos, pasados y presentes, concebidos aquí como "progresistas", reside en el temprano distanciamiento de los socialismos revolucionarios del ideal emancipatorio ilustrado, distanciamiento que devino en abierto antagonismo práctico a partir de la revolución soviética y el posterior desarrollo de las dictaduras y totalitarismos comunistas. Ese antagonismo implicó que la naturaleza de las cuestiones que fueron adquiriendo relevancia y vigencia en las agendas sucesivas de uno y otro fue, y en la medida en que el socialismo revolucionario posea alguna vigencia hoy, es muy distinta. Ello no es obstáculo para reconocer que parte de la "caja de herramientas" del progresismo ha descansado en el marxismo, aún cuando ello sea más que discutible en el presente.

La dependencia anotada del progresismo y la política progresista respecto de las ciencias sociales presenta a la vez un anverso. Al camino de ida desde la teorización, el análisis y la investigación a la política, corresponde un camino de vuelta desde esa última hacia las primeras.

Los logros, y sobre todo los fracasos y dificultades que la política va generando y encontrando en su devenir, alimentan la agenda de los esfuerzos intelectuales más rigurosos por explicar, comprender y aún anticipar. Se ha demostrado que la agenda de las 
disciplinas sociales y la agenda de cuestiones de las sociedades nacionales, agenda esta última que van explicitando y conformando los actores políticos relevantes, en un sentido amplio, se intersectan de manera importante. Una disciplina es vital, y no mero academicismo, en la medida en que es capaz de conservar un cordón umbilical sólido con esas agendas de cuestiones político-culturales a partir de las cuales la sociedad es consciente de sus satisfacciones, sus malestares, sus angustias, sus carencias, sus momentos de honor y sus momentos de oprobio. Ello justifica que en un contexto académico se tome como objeto de reflexión lo que se considera que son hoy las cuestiones cruciales en la agenda del progresismo, independientemente del compromiso político que se tenga con él.

Las reflexiones que siguen no aspiran a mostrar un listado exhaustivo de lo que se podría llamar "cuestiones cruciales para el progresismo de hoy", ni tampoco constituir una reflexión cabalmente rigurosa sobre las interrogantes que se plantean. De hecho, se ha optado por suprimir referencias bibliográficas, citas a pié de página y reenvíos a autores. La lectura adecuada podría ser la propia de quien enfrenta un conjunto de simples provocaciones o estímulos para continuar por cuenta propia la meditación.

Los temas presentados se han tratado fundamentalmente como tensiones, dilemas o disyuntivas. Ello no es un mero artificio retórico, o un expediente para soslayar la responsabilidad que supone una toma de posición. Dejar sin resolver una tensión o una disyuntiva, y hacerlo de buena fe, es perfectamente legítimo si sobre los términos de la tensión o disyuntiva pesa una incertidumbre irremovible por ahora. Lo privilegiado de establecer una relación de recíproca alimentación entre la posibilidad de saber y la posibilidad de actuar reside en una tercera posibilidad: la de mantener en suspenso la necesidad de decisiones, apostando a que, al preservar por ahora la tensión o disyuntiva, su elaboración intelectual permita, o remover grados importantes de incertidumbre, o al menos, que cuando las urgencias de la práctica impongan la necesidad de decidir, el compromiso se adopte en el contexto de la mayor razonabilidad alcanzable.

Por otra parte, lo que la realidad plantea hoy al progresismo están lejos de ser certezas. Por el contrario, pese a ciertos compromisos y decisiones básicos ya asumidos, que no pueden sino proyectar larga sombra sobre el futuro, lo que alimenta las posibilidades de la agenda progresista son inquietudes relevantes, malestares, aún angustias, intelectualmente expresadas en disyuntivas provistas de incertezas más que importantes. Por consiguiente, la manera escogida para pensar y escribir sobre las cuestiones que le atañen, más que defendible, es válida.

\section{2. ¿Globalización de las cuestiones?}

Durante el siglo XX, en América Latina, en los países del Tercer Mundo, y en Chile en particular, los movimientos y corrientes políticos que contemporáneamente han devenido o confluido en lo que hoy se llama progresismo se articularon y adquirieron sus identidades en términos de análisis o reflexiones político-culturales uno de cuyos rasgos principales residió en enfatizar la especificidad histórica -socioeconómica, sociocultural y 
sociopolítica- de las respectivas sociedades nacionales, por oposición a especificidades históricas no sólo distintas, sino aún antagónicas: las realidades de los países centrales desarrollados o de capitalismo a la sazón concebido como maduro.

Esta reivindicación de especificidades históricas propias, no reducibles ni absorbibles por marcos teóricos y análisis con pretensiones universalistas, cumplió no sólo funciones como herramienta político-estratégica, útil en el fragor de las luchas coyunturales y situacionales, sino que impulsó también desarrollos intelectuales originales, con mayores o menores connotaciones políticas, orientados a la comprensión y producción de conocimientos que, justamente en cuanto guardaban fidelidad a esas especificidades históricas, podían alcanzar una validez que le estaba negada a las elaboraciones provenientes de los Estados Unidos, Europa y aún del mundo cultural comunista de la Europa Central articulado en torno a la Unión Soviética.

Los objetivos de esa reacción, que podría caracterizarse de anti occidental, fueron varios. Ciertamente, se dirigió contra los desarrollos sociológicos, politológicos, antropológicos y los provenientes de la economía profesional, todos ellos generados en los "establishments" académicos estadounidenses y europeos. El funcionalismo, el paradigma positivista-empírico, las elaboraciones matemático-formalistas, los marcos teóricos basados en los conceptos de modernización y desarrollo, sobre todos ellos recayó un estigma que quizás proyecta larga sombra hasta hoy. La suerte de clásicos no marxistas como Weber o Durkheim, pese a que se les dotó de una cierta respetabilidad académica, no fue muy distinta en términos de su efectivo impacto en la reflexión y la investigación. Pero la reacción no se restringió a lo que provenía del mundo académico occidental establishmentario. Igualmente se constituyeron en blancos tanto las corrientes marxistas occidentales que cabría calificar de académicas, como los marxismos originados en el ámbito soviético y comunista. Si una figura como Gramsci adquirió tempranamente un cierto prestigio, con anterioridad al inicio de la "liberalización" de las izquierdas latinoamericanas asociada a los procesos de transición democrática y a fenómenos concomitantes con la descomposición del mundo comunista como es el caso del eurocomunismo, "liberalización" que a su vez es parte del tránsito desde esas izquierdas hacia el progresismo contemporáneo, ello probablemente obedece mucho más a esa suerte de profunda especificidad italiana que le es propia, mas que a lo que sustantivamente su reflexión y análisis significa. En efecto, hoy en día, la obra gramsciana aparece irrelevante, y ello mucho menos porque revolución y socialismo sean malas palabras, o nociones obsoletas, sino mucho más en razón de ese carácter de radicalmente históricamente situada que esa obra efectivamente posee.

La faz positiva de esta reacción no fue desdeñable. Desde la temprana valoración y reivindicación de figuras como Mariátegui, pasando por la multiplicidad de ensayistas latinoamericanos que florecen desde los años cuarenta del siglo XX en adelante, para culminar en el paradigma de la dependencia y del subdesarrollo como fenómeno con leyes y lógicas propias -el desarrollo del subdesarrollo-, no subsumible en una periodización de etapas sucesivas, casi necesarias para cualquier sociedad nacional, quizás todo ello constituye uno de los momentos más fecundos en la creación político-cultural latinoamericana. En todo caso, si de originalidad e identidad propia se trata, difícilmente emulable por la producción político-cultural contemporánea. 
En cuanto a reivindicación de especificidad histórica, la situación sitúa hoy al observador en las antípodas. Es difícil encontrar autores, posiciones u opiniones que no partan de la premisa, usualmente implícita, que los contenidos del debate progresista en Europa, Estados Unidos y otras realidades que se tiende a calificar como en un estadio de desarrollo superior al propio son relevantes en casos como el de Chile. Ello implica no sólo atenuar esa afirmación de especificidad o particularismo antes referida. Parece ir más allá: se estaría afirmando que esencialmente los problemas y desafíos son los mismos en estas diversas realidades. ¿Cómo justificar ésto?

Marx decía que la clave de la comprensión de la anatomía del mono residía en la comprensión de la anatomía del hombre: las formas capitalistas maduras, más avanzadas, prefiguraban el destino de las formaciones sociales más atrasadas.

Quizás hoy se puede ser más radical y afirmar que la anatomía de sociedades tan diferentes como Chile, el Reino Unido, España o Francia es, en un cierto sentido, muy semejante. Estarían afectadas por la dinámica y profundización de una modernidad capitalista que es esencialmente la misma. Por consiguiente, existiría una comunalidad de desafíos y problemas, que puede ser más relevante que las especificidades o particularismos propios de las sociedades nacionales.

Esta premisa está íntimamente vinculada con el juicio, probablemente compartido en términos muy inclusivos, sobre la naturaleza inédita o cualitativamente nueva del fenómeno de globalización como lo distintivo de la época o período histórico que se inicia en las últimas décadas. La noción de una economía-mundo es, en cuanto invención intelectual o teórica, anterior al fenómeno de globalización y pretendió describir y dar cuenta, con validez, de una realidad que llevaba ya varios siglos en desarrollo. No obstante, si bien siempre se aseveró que el progreso de esa economía-mundo no podía sino afectar las formaciones sociales que comprendía, expresadas políticamente en estados nacionales, regiones o subregiones, teóricamente esos efectos o articulaciones tenían una jerarquía inferior a las especificidades o particularidades propias de cada unidad o tipo de unidad a partir de las cuales esa economía-mundo se iba desarrollando. Puesto de otra manera, la lógica de la dinámica de la economía-mundo era una lógica de segundo nivel, que más que explicar las lógicas específicas o particulares de una formación social o tipo de formaciones sociales, era mayoritariamente explicada por esas lógicas, o bien contribuía, quizás de manera secundaria, a la dinámica de las segundas. Por consiguiente, desde esta comprensión, los problemas de cada unidad, o tipos de unidades, poseían una cierta identidad e irreductibilidad que se proyectaba también en las posibilidades de respuestas político-prácticas a esos problemas. Ni los problemas eran los mismos para todos, ni las maneras de atacarlos podían ser las mismas.

A lo que apunta la noción de globalización es a una creciente universalidad de la naturaleza de las estructuras y procesos; por consiguiente, a una creciente universalidad de los problemas y del repertorio de posibles respuestas a esos problemas. A la vez, ese repertorio se muestra también crecientemente restringido, y esta disminución de grados de libertad en la conducción y política desde el punto de vista de las sociedades nacionales es parte esencial del notable aumento, históricamente también inédito, en la frecuencia y 
densidad de las interacciones de toda clase entre las formaciones sociales: comerciales, culturales, de poder. etc. Los "juegos entre naciones" se han complejizado enormemente, pero al mismo tiempo el número de jugadores "jugando un mismo juego" aumentó más allá de lo que ha sido hasta ahora la experiencia histórica humana. Tanto la complejidad como el número disminuyen significativamente la autonomía de los actores en la identificación e implementación no sólo de comportamientos estratégicos, sino respecto de una gran variedad de actividades. La misma creación artística, por ejemplo, es capturada y absorbida por esa complejidad y "necesidad de referencia a otros", con la universalización concomitante de cánones y estéticas, lo cual acarrea cosas positivas, pero inexorablemente supone costos en la autonomía.

Ciertamente, las sociedades nacionales difieren entre sí. Por ejemplo, la escasez, si bien una constante universal, presenta órdenes de magnitud muy distintos al contrastar las realidades latinoamericanas con las de los países desarrollados. Lo que varios afirman y muchos parecen aceptar es que esa diferencia es de gran relevancia, pero en cuanto problema y desafío es procesado por estructuras, instituciones y ordenamientos cada vez más similares $\mathrm{y}$, en proporción creciente, meta-nacionales. Por consiguiente, la universalidad del problema se asocia hoy a una universalidad de respuestas, y ello no fue así en el pasado.

¿ Por qué la globalización de las cuestiones plantea al progresismo una disyuntiva?. En los orígenes ilustrados, el ideal emancipatorio poseía una connotación individual o personal: la "iluminación" residía en abandonar su inmadurez auto-inflingida, la incapacidad de emplear la propia inteligencia sin la guía de otros, y auto-inflingida en razón de derivar de la falta de determinación y coraje para hacerlo ${ }^{39}$. Pero ya en esos inicios estaba claro que ese ideal necesariamente tenía una proyección colectiva: necesitaba al menos de condiciones políticas generalizadas: por ejemplo, libertades públicas. Desde el siglo XVIII en adelante, adquirió progresivamente connotaciones colectivas o societales cada vez más fuertes. En esa comprensión, emancipación adquirió también el significado de la capacidad de la sociedad nacional de "pararse sobre sus propios pies", para muchos algo íntimamente fusionado con las posibilidades de emancipación personal o individual.

El tema de la "globalización de las cuestiones" y el tema mismo de la globalización no son por consiguiente pacíficos en el seno del progresismo. En rigor, ideas, movimientos y expresiones "globalofóbicas" pertenecen, por lo menos hasta ahora, al mundo progresista. Lo mismo cabe decir de posiciones cuya aceptación del fenómeno como dato irremovible y que está allí y aquí para quedarse incorpora conjuntos de matices de naturaleza tal como para diferenciarlas sustantivamente de posiciones cuya aceptación de él es más cabal, sujeta a menos clasificaciones.

La globalización de las cuestiones, expresada entre otras cosas en referencias reiterativas a los debates europeos, encierra una tensión. Si la globalización misma es un dato, la característica de un período nuevo en una historia mundial que comienza a devenir historia universal, cómo entonces religar lo nuevo a las raíces culturales primordiales del

${ }^{39}$ La referencia es al opúsculo de Kant, Qué es Ilustración. 
progresismo, y cómo proyectar esa religación a una práctica política cuyo escenario y sentido son, también inevitablemente, de naturaleza "doméstica".

\section{Integración socioeconómica}

Ya más sustantivamente, una de las primeras cuestiones centrales en la agenda progresista contemporánea es la de la integración socioeconómica de las personas en el contexto de la naturaleza y dinámica del capitalismo contemporáneo.

En los países centrales o desarrollados, el desafío de integración socioeconómica tuvo durante el siglo XX dos respuestas progresistas, articuladas entre sí y principalmente protagonizadas por las social democracias: el keynesianismo y las prácticas keynesianas, posibilitadores de integración vía empleo, y el Estado de Bienestar, reforzador y complementario del keynesianismo respecto de necesidades y problemas no superables vía mercado: vivienda, salud, seguridad social, educación.

Ambas respuestas entraron en contradicción con la nueva modernidad capitalista en progreso: la prefiguración y virtual consolidación de lo que Ulrich Beck llamó ya en 1986 la sociedad del riesgo. El Estado de Bienestar comenzó a debilitarse significativamente durante el último cuarto del siglo $\mathrm{XX}$, tendencia que continúa hasta hoy. El keynesianismo cedió el paso a nuevas teorizaciones y políticas -neoliberalismo o "nueva macroeconomía"-, hasta ahora relativamente hegemónicas.

Teóricos e ideólogos diversos han procurado identificar nuevas modalidades de políticas sociales, que rescatando la misión básica del Estado de Bienestar, no sean contradictorias con la dinámica de la nueva modernidad capitalista y en consecuencia no afecten negativamente las potencialidades de crecimiento. A la vez, diversos gobiernos han puesto en práctica políticas inspiradas en esas concepciones. Por ejemplo, redefiniendo la titularidad de beneficios en términos de una ciudadanía social que comporta tanto derechos como obligaciones. Por consiguiente, una ciudadanía social que comporta responsabilidades: exigencia de esfuerzos personales por inserción en mercados laborales, responsabilidad individual por condiciones facilitadoras de la propia salud, etc.

Hasta ahora, estas teorizaciones han mostrado escasa efectividad. Políticamente, podría decirse que han fracasado, si se atiende a los desenlaces electorales europeos recientes, adversos a fuerzas políticas progresistas.

En el caso de Chile, como probablemente en el de los otros países latinoamericanos, el examen de la cuestión de la integración social exige abordar el tema más general del rol del Estado en la época contemporánea en este tipo de sociedades nacionales.

El rol del Estado chileno, en el presente período histórico, consiste en articular dos grandes conjuntos de tareas, o funciones, si se prefiere. Ambos conjuntos son igualmente prioritarios: el desempeño exitoso o satisfactorio en uno de ellos es condición necesaria para el desempeño satisfactorio en el otro, y viceversa. 
La primera gran función, reside en gestionar el tipo de capitalismo propio del mundo contemporáneo, procurando mantener los valores de las variables cruciales del sistema dentro de rangos "razonables".

La segunda gran función, consiste en ir generando y manteniendo a través del tiempo, niveles de integración social, lo que es sinónimo de niveles de cohesión social, por sobre valores críticos, posibilitando grados de gobernabilidad suficientes para el desempeño de la primera función. Una de las afirmaciones que usualmente se hacen, que aquí se acepta, es que el mal desempeño económico afecta negativamente la capacidad de producir integración social -de ahí la relación de necesidad entre ambas funciones.

Ambas grandes funciones denotan dos conjuntos de tareas diversas, que adquieren prioridades distintas según etapas y situaciones, susceptibles de llevarse a cabo mediante instrumentos distintos. Quizás la polémica política-económica y política-social verse hoy mucho más sobre instrumentos que sobre funciones o tareas, debido a la inexistencia de algo así como un consenso, con alguna fundamentación científica, que establezca una suerte de relación unívoca entre tarea e instrumento. Pero, por otra parte, los instrumentos no son generalmente neutros respecto de otros valores, distintos de la eficacia o eficiencia en el cumplimiento de la tarea, lo que ciertamente refuerza la naturaleza eminentemente polémica de la materia.

La función de gestión del capitalismo incluye algunos tipos básicos de tareas: preservación de una trayectoria macroeconómicamente equilibrada; empuje al máximo posible de la tasa de crecimiento, con el límite de no generar impactos desequilibrantes significativos; e identificar e implementar políticas anticíclicas que, en las etapas recesivas, posibiliten mantener condiciones favorables al relanzamiento en las fases dinámicas $\mathrm{y}$ expansivas.

El desempeño de estos tres tipos básicos de tareas tiene como escenario una realidad socioeconómica que no es homogénea. En los hechos, una misma institucionalidad económica alberga al menos dos clases de capitalismo, dos clases al menos de mercado, podría decirse.

El núcleo duro de la economía lo constituye un capitalismo globalizado, en muchos sectores "informacionalizado", competitivo, crecientemente intensivo en tecnología y capital humano, con un potencial decreciente de generación de empleo. Independientemente de la cuestión sobre la agregación de valor, habría que incluir aquí los grandes sectores exportadores. Este núcleo duro es el responsable por el dinamismo de la economía, salvo en cuanto a empleo. El papel estratégico crucial de este capitalismo implica entonces para el Estado una función de facilitamiento, de generación de entornos institucionales, de políticas, bienes públicos e incentivos que pongan al núcleo duro "en situación de" desempeñarse satisfactoriamente. Se ha afirmado aún que en el modelo de capitalismo contemporáneo "el" interés público o bien común que debe guiar al Estado, a diferencia del interés por la rentabilidad que orienta a las empresas, es la competitividad de la economía nacional. Sin extremar las cosas, se puede afirmar que hay una responsabilidad estatal en cuanto al desempeño del núcleo duro. 
La pregunta es si el dinamismo de este núcleo duro tiene la capacidad de producir suficiente integración social como para sustentar la gobernabilidad requerida para una gestión satisfactoria de la economía, en un contexto políticamente democrático. Ese dinamismo produce en general integración social respecto de un sector minoritario de la sociedad -solidaridad orgánica podría decirse, respecto de los involucrados protagónicamente en las redes del núcleo duro-, independientemente de la fase del ciclo económico en que se encuentra la economía, pero aún en fases expansivas no es capaz de generarla para la gran mayoría. Ello se explica no sólo por la capacidad decreciente de generación de empleo del sector, sino y quizás de manera más importante, por su naturaleza concentradora: acumula crecientemente riqueza, poder, influencia, prestigio, oportunidades, hegemonía cultural, acceso mediático y capital cultural de alto nivel en un número relativamente pequeño de redes. Los mercados que lo constituyen carecen significativamente de una cobertura poblacional suficiente como para generar en la gran mayoría la solidaridad orgánica propia de los mercados. Una de las grandes falacias neoliberales reside en postular una institucionalidad económica que alberga un sólo gran mercado homogéneo, capaz de producir integración social en el conjunto de la sociedad.

Respecto de la otra clase de mercados, varios de ellos pueden generar integración social en las fases expansivas del ciclo a través de la generación de empleo y acceso al consumo. Aún en estos casos, la realidad parece mostrar que el ciclo en la economía mundial globalizada tiende a comprimir sus fases. En términos del ciclo de vida promedio de los agentes o sujetos de estos mercados, ello implica una trayectoria de vida azarosa, signada por incertidumbre y eventos "catastróficos" frecuentes (desempleo, subempleo, descenso en ingresos, etc.). Ello contrasta con las expectativas generadas por la expansión de la cobertura del sistema educacional, incluyendo el acceso a la educación superior por capas de clase media menor o aún sectores pobres: básicamente, expectativas de movilidad social ascendente, mayor comodidad material y mayor seguridad. En la larga duración, estos mercados son por consiguiente deficitarios en cuanto a producir integración social. La integración hay que generarla por medios distintos al mercado, más allá del caso de la población en situación de pobreza y pobreza extrema o dura, y esa necesidad define la segunda gran función para el Estado.

En su operación práctica, la institucionalidad económica también es deficitaria en la producción de integración social respecto de los agentes organizados como mediana, pequeña y micro empresa. La experiencia muestra que estos sectores son extremadamente vulnerables al movimiento cíclico de la economía, particularmente las empresas pequeñas y microempresas. En ausencia de políticas públicas sistemáticas, que impliquen intervención estatal proactiva, la incertidumbre y carácter azaroso de las trayectorias individuales padecidas por los actores de este sector, por una parte generan frustración y alienación en ellos, y por otra erosionan la validez y seducción de este tipo de situaciones como modelos de rol o destino individual deseable y viable para el conjunto de la sociedad. La "empresarización" masiva como proyecto y estrategia de integración -por consiguiente, como instrumento de producción de cohesión social- es meramente ideología.

Las consideraciones anteriores ponen en evidencia la debilidad de las aproximaciones y maneras de comprensión de las políticas sociales hoy en uso, ciertamente 
uno de los instrumentos por excelencia en cuanto a producción de integración. Aún en el caso de las políticas nítidamente asistenciales orientadas hacia los sectores de pobreza, pobreza dura y otros grupos vulnerables, la idea que prevalece es que, en su operación, incorporan a los beneficiarios a un proceso de duración variable, cuyo desenlace natural y deseable es la integración vía los mercados de trabajo formales o vía ocupaciones en que finalmente la persona es capaz de valerse por sí misma, tal como lo expresa el manido aforismo que postula como objetivo "no entregar peces, sino la caña de pescar y las habilidades para capturar los peces". No se trata de cuestionar esta visión, sino de subrayar la alta probabilidad de que su eficacia sea bastante más débil de lo que se supone. Como ya se dijo, esta debilidad está presente aún en políticas como las educacionales, de naturaleza promocional, donde el desenlace "natural", consistente en el ingreso al mercado de trabajo, parece como algo obvio, fuera de discusión.

En el fondo, esta visión descansa no sólo en la premisa de una normalidad económica altamente dinámica y estable, sino también en una sobreestimación de la racionalidad económica instrumental, individual y grupal, como el "dios de la maquina", único y excluyente, que da cuenta del movimiento de la sociedad. No es del caso desvalorizar la importancia de esta clase de racionalidad en la operación del capitalismo de mercado contemporáneo, sino simplemente destacar su debilidad relativa en la producción de integración social.

En este punto reside otra de las tensiones, que en definitiva se traduce en una disyuntiva, que afectan al progresismo hoy en día. La premisa recién referida tiende a ser aceptada, de manera implícita, sin mayor cuestionamiento. Buena parte de los dilemas que se le plantean a las corrientes progresistas en sus actividades político-prácticas, incluidas las de gobernar y definir e implementar políticas públicas -los Escila y Caribdis que reiteradamente enfrenta-, derivan de esa aceptación implícita y acrítica de la premisa en cuestión. Puesto de otra manera, se trata de dilemas auto-infligidos, originados en el ignorar o pasar por alto que la integración social efectiva responde también a motivaciones distintas de las que supone la inserción formal en mercados, es decir, en las redes que constituyen la división social del trabajo. Esta falencia es difícil de explicar si se constata que las tradiciones intelectuales que confluyen en el progresismo contemporáneo exhiben una riqueza de análisis y aproximaciones al tema de la integración social que supera con creces la de las tradiciones liberales más químicamente puras.

Un desempeño satisfactorio de la función estatal de producir integración social requeriría descansar también en racionalidades instrumentales de otro tipo, que atienden necesidades distintas de las económicas -por ejemplo, necesidades de poder o protagonismo, expresadas en las reivindicaciones por participación o "empoderamiento", o necesidades de seguridad cotidiana no económicas-, provistas de una connotación grupal o más colectiva, o racionalidades no instrumentales, que apuntan a satisfacer necesidades expresivas, estéticas, de relacionamiento interpersonal, de identidad, de sentido de pertenencia.

Si bien no es del caso identificar aquí instrumentos específicos que, basados tanto en una concepción más amplia de racionalidad como en la satisfacción de necesidades no estrictamente económicas, permitan superar la debilidad de visiones y prácticas 
circunscritas a la racionalidad económica instrumental, caben algunas reflexiones generales sobre la materia.

Primero, puede no tratarse de instrumentos de rol único. Por ejemplo, una política específica de subsidio asistencial es susceptible de implementarse bajo una modalidad más compleja que la que implica una simple cadena burocrática clásica, que va desde el servicio público o el funcionario a la entrega de la suma transferida al usuario, de manera de generar a la vez otros "valores", que implican un beneficio individual o grupal complementario del subsidio. La noción de "añadir valor público" mediante la acción de agentes estatales en la prestación de un servicio cuyo "valor" es muy específico, noción que comienza a popularizarse, apunta a esta posibilidad de obtener una variedad de resultados que trascienden el beneficio específico que implica la prestación, reforzando así la producción de integración social.

Segundo, desde la óptica aquí asumida cobran relevancia tanto las políticas como modalidades de implementación de políticas que poseen la capacidad de generar "comunidades" o redes sociales, que ciertamente pueden tener, entre otros, beneficios con clara connotación económica en relación con la posición o situación en un mercado. Por ejemplo, una red bastante integrada y sólida de microempresarios o empresarios pequeños con un giro común puede robustecer la situación de mercado de todos, añadiendo además otros beneficios no económicos, uno de los cuales es el hecho mismo de estar asociados: satisfacción de una necesidad de sociabilidad. Un tejido de sociabilidad y asociatividad societal, crecientemente más denso y robusto, sin duda hace una contribución importante a la obtención de niveles más altos de integración social.

Tercero, y complementariamente con lo anterior, el déficit en comentario inherente a la institucionalidad económica pone de relieve la importancia de la trama institucional en general. Uno de los efectos negativos de la hegemonía cultural de la racionalidad económica es la subestimación de las instituciones en general, salvo la institucionalidad propia del mercado, que es además presentada, en términos de la lógica que le es peculiar, como paradigma de funcionamiento institucional. Las instituciones no sólo constituyen "reglas del juego" determinantes del movimiento de la sociedad. A la vez, en cuanto abstracciones reificadas -reificación por lo demás necesaria-, son "sujetos" con los cuales identificarse; adicionalmente, "sujetos" que conforman un paisaje societal altamente estable. El enriquecimiento y valorización premeditados de ese paisaje institucional es otro fuerte componente de la producción de integración social.

\section{Gobernabilidad: ¿cómo y en qué condiciones?}

Gestionar con éxito el capitalismo contemporáneo, en los términos arriba señalados, implica para las corrientes progresistas tipos de comportamiento político-estratégico y táctico que no sólo faciliten niveles altos de gobernabilidad, sino que de hecho promuevan la gobernabilidad como objetivo principal y permanente. 
De hecho, esta meta de obtención de gobernabilidad y preservación de ella por sobre umbrales críticos está íntimamente relacionado con esa otra tarea primordial que es impulsar procesos efectivos de integración social. De acuerdo a los ideales progresistas, la integración social tiene un valor en sí misma, pero en términos de práctica política posee también una connotación instrumental positiva: cuanto más altos los niveles de integración social, mayores las ventajas y condiciones facilitadoras de obtención y mantención de gobernabilidad. Se podría decir que si la integración socioeconómica es alta, ella genera un capital político movilizable por partidos y gobiernos al enfrentar problemas de gobernabilidad.

Objetivamente, lograr gobernabilidad no es para el progresismo tarea fácil. Aún en las fases expansivas del ciclo económico, gestionar la nueva modernidad capitalista, de por sí compleja, pletórica de incertidumbre y frecuentemente turbulenta, implica disyuntivas fuertes, no sólo en razón de la exigencia de decisiones muchas veces contradictorias con las posturas y compromisos de valor propios del progresismo, sino también con necesidades político-electorales. Se trata con mayor frecuencia de lo deseable de decisiones que, al menos en el corto plazo, hieren intereses o vulneran expectativas de los "electorados naturales" de estos partidos.

Si la cuestión de la gobernabilidad implica tensiones como regla general, esas tensiones se intensifican durante las fases contractivas del ciclo económico. Como se dijo, los mercados y las políticas sociales públicas tienden a ser deficitarias en la generación de integración socioeconómica y su correlato: cohesión social. Sobre la base del malestar, insatisfacción y frustración que esos déficits han venido acumulando, los "tiempos económicos duros" gatillan escalamientos de demandas y fenómenos de movilización social más intensos y abiertamente confrontacionales que en los tiempos de bonanza. El manejo o gestión de esos procesos, los grados de libertad para la adopción de decisiones, los costos políticos de esas decisiones, todo ello entra fácilmente en contradicción tanto con principios y las preferencias que de esos principios se siguen, como con intereses estrictamente más políticos, como chances electorales, popularidad masiva, cohesión partidista, armonía con actores relevantes de la sociedad civil.

El ámbito donde mejor se manifiesta esta tensión que plantean los problemas de gobernabilidad es en el de las decisiones impopulares. La capacidad de adoptarlas es ciertamente una de las dimensiones más relevantes de la gobernabilidad, particularmente ante una realidad contemporánea cuya riqueza en desafíos que exigen respuestas políticas dotadas de eficacia en plazos comparativamente largos, pero que al mismo tiempo implican costos en cortos o medianos plazos cuya inclusividad social es importante. Se trata de los clásicos dilemas caracterizables mediante el pan hoy, hambre mañana, que si bien se intensifican durante los "tiempos económicos duros", la verdad es que están presentes, con mayor frecuencia de lo que sería deseable, aún en tiempos de bonanza. Por consiguiente, las tensiones que plantea la necesidad de gobernabilidad al progresismo desbordan las fases contractivas del ciclo económico. Son un rasgo mucho más permanente de las situaciones en que hoy tiene que desenvolverse.

Vale la pena ejemplificar el punto. Se ha señalado con razón que el gasto social dirigido especialmente a los pobres, gasto que puede actuar como complemento del 
autoseguro y de sustituto del seguro de mercado, que se tornan insuficientes durante las recesiones, debería tener un comportamiento anticíclico. El problema reside en que las decisiones constitutivas de un comportamiento tal son difíciles. De hecho, la conducta de los hogares pobres frente al riesgo es más racional que la del progresismo, esté en el Gobierno o en la oposición. Los hogares pobres refuerzan el autoaseguramiento ahorrando en los tiempos buenos; enfrentan las recesiones breves o leves, percibidas como transitorias, recurriendo a activos como la mano de obra familiar para amortiguar el descenso de ingresos; sólo en recesiones largas y profundas recortan gastos en educación y salud. Inversamente, la implementación de una política pública que responda a ese tipo de racionalidad es extremadamente difícil, no por ausencia de información y conocimiento, sino por la interacción de restricciones políticas y económicas que obstaculizan la acumulación de reservas en épocas de bonanza, reservas que serían susceptibles en los tiempos críticos. Las razones son obvias: controlar las presiones por expansión de gasto en períodos de crecimiento es una tarea impopular, que implica sobrellevar y controlar costos políticos no menores, como también lo es blindar el gasto social focalizado durante etapas contractivas. En ausencia de un sistema nacional permanente, bien diseñado y financiado, la opción es recurrir al endeudamiento en los mercados financieros durante los "malos tiempos", para pagar durante los "buenos tiempos". El problema es que durante los "malos tiempos" tiende a no haber disponibilidad de recursos para ese fin porque los mercados de capitales se comportan también de manera procíclica ${ }^{40}$.

Las tensiones, dilemas y disyuntivas que la cuestión de la gobernabilidad plantea al progresismo no sólo lo son de situaciones en que los partidos progresistas son gobierno. Se repiten también en las situaciones en que se encuentran en la oposición, con el agravante de que al ser oposición los incentivos a guiarse puramente por una ética de convicción, manteniendo una celosa fidelidad a las preferencias inmediatamente derivadas de principios, soslayando las mediaciones que impondría una ética de responsabilidad, tienden a ser mucho más abundantes e intensos. No obstante, pese a esa opción estratégica facilitada por la situación, la gobernabilidad y la responsabilidad por ella sigue siendo un problema, que continúa planteando tensiones. En parte, porque desatenderla lleva a ese efecto perverso sintetizado en aquello de que él que siembra vientos, cosecha tempestades: la desatención lo haría cargar con un pesado fardo, que le dificultaría asumir una posición de responsabilidad en el evento de retornar a ser gobierno. Pero también porque, en la medida en que no haya una decisión de devenir antisistema o extrasistema, el progresismo en la oposición requiere de construir confianza, credibilidad y reputación de responsabilidad, precisamente como condiciones de preservar sus chances como un protagonista político eficaz y como un contendor por el poder. Por consiguiente, la gobernabilidad como cuestión, con sus implicaciones de tensión, dilema o disyuntiva, persiguen al progresismo, como la sombra al cuerpo, sea gobierno, sea oposición.

En el límite, la cuestión de la gobernabilidad y sus implicaciones puede llegar a plantearse en términos de una oposición entre la opción por un control y conducción

\footnotetext{
${ }^{40}$ Véase Víctor E. Tokman, Hacia una visión integrada para enfrentar la inestabilidad y el riesgo, trabajo presentado al Taller sobre Macroeconomía y Pobreza, realizado en Santiago de Chile, diciembre 2001, CEPAL.
} 
sociopolíticos democrático-libertarios por una parte, y la opción por un control y conducción sociopolíticos represivos y socialmente desmovilizadores, y las cosas tienden a acercarse a semejante límite en tiempos difíciles, particularmente en el ámbito del desempeño económico. En el caso de las derechas, hay una preferencia casi espontánea por la segunda opción, y en la medida en que ocupan el poder gubernamental es predecible un rápido deslizarse hacia prácticas de ese carácter. Aún en posiciones opositoras, las apreciaciones críticas de la situación desde las derechas implican o sugieren, con las sutilezas y resguardos debidos a lo "políticamente correcto" y a las restricciones derivadas de evitar costos políticos como impopularidad, la necesidad de un mayor autoritarismo.

A lo último colabora el diagnóstico recurrente de que las dificultades se generan en gran medida por la naturaleza errónea, apartada de la corrección científico técnica y del conocimiento científicamente validado, de las políticas que los gobiernos progresistas implementan. A la vez, parte importante de las dificultades que padece el progresismo en estas materias tienen que ver con la predisposición a aceptar acríticamente y sin mayores matices la premisa de la que parten esos diagnósticos. Curiosamente, a las corrientes progresistas les cuesta reconocer la naturaleza eminentemente política de los problemas de gobernabilidad y de las soluciones a ellos. En el marco de la inevitable tensión descrita, el reconocimiento de la naturaleza esencialmente política del problema haría una contribución importante al manejo de ella.

\section{EI Norte político: lo clásico versus lo emergente}

Una tercera cuestión crucial versa sobre la incertidumbre respecto de lo que se podría llamar el Norte político básico o primordial que debería orientar el quehacer político. En efecto, parte de los cambios que viven hoy las sociedades nacionales residen en la emergencia de formas políticas nuevas o posibles, formas que en algún sentido se enfrentan a las formas políticas modernas clásicas.

El debilitamiento de la soberanía estatal, en su conceptualización clásico-moderna, en razón de la profundización de la globalización, rasgo esencial de la nueva modernidad capitalista, es hoy casi un lugar común. Pero a ello hay que agregar la emergencia de diversas pretensiones, más o menos mayoritarias, más o menos minoritarias, de efectividad político-cultural hasta ahora también variable, que contribuyen a erosionar ese Norte, durante tanto tiempo asumido casi como algo natural en el quehacer político, que ha sido el estado-nación soberano.

Entre esas pretensiones se pueden enumerar las aspiraciones a transitar a formas más federalistas y menos unitarias de gobierno central; el empowerment o "empoderamiento" de formas políticas regionales, subregionales y locales; descentralización de ámbitos diversos de los aparatos de Estado; pretensiones de reforzamiento de la sociedad civil, lo que no es sino sinónimo de radicación de poder y capacidad de decisión en una diversidad de asociaciones, organizaciones y movimientos clásicamente "no políticos"; pretensiones de autonomía radical para territorios étnicamente homogéneos y minoritarios respecto de la sociedad nacional; desvalorización creciente de 
las formas de democracia representativa (particularmente, parlamentos o congresos nacionales) y de sus agentes "naturales" -los partidos políticos-, asociada a la valorización creciente de formas de democracia directa (referéndum, plebiscito, iniciativa popular de ley, mandatos revocables).

Ciertamente, sería poco serio anticipar algo así como una extinción del estado nacional en el tiempo próximo. No obstante, al comparar la práctica política más que secular, orientada por la idea de Estado, de poder nacional, de prestigio y destino nacional, de política como lucha por el control del Estado, de vigorización del propio Estado en términos de competitividad sistémica en el mundo, todos los fenómenos o posibilidades mencionados apuntan a un horizonte mucho más incierto en cuanto a referentes políticos básicos para el quehacer político.

Todos esos fenómenos o posibilidades, conceptualizables como otras tantas "causas", son causas que se plantean hoy por muchos como causas progresistas. Desafortunadamente, con frecuencia ello se hace de manera facilista y evitando una pregunta que, al menos desde visiones progresistas, es más que relevante: ¿qué agencia puede sustituir al Estado como motor de una homogeneidad social importante, que en las mejores tradiciones progresistas siempre se ha asociado al avance en valores como libertad, igualdad, solidaridad, movilidad social masiva, cohesión social?

Así, una realidad política hoy cambiante y dinámica, después de un par de siglos de una relativa estabilidad, va construyendo un paisaje de formas nuevas y posibilidades institucionales cuyo significado, en términos de sus proyecciones en medianos y largos plazos, está provisto de ambigüedades más que importantes. Esas ambigüedades constituyen otro de los componentes del campo de tensiones en que se desenvuelve el progresismo.

\section{Despolitización versus repolitización}

La evidencia empírica disponible apunta a una presencia bastante consolidada de fenómenos contemporáneos de despolitización. Esos fenómenos admiten explicaciones diversas y competitivas entre ellas. Se pueden interpretar como el efecto de un proceso, más o menos intencional, de transformación cultural, funcional a la operación de la nueva modernidad capitalista y a las exigencias de gobernabilidad que impone. Se trataría de una transición desde una cultura ciudadano-céntrica a una privado-céntrica. O bien, se pueden interpretar como respuesta al ya referido proceso de desvalorización de las formas políticas de la modernidad clásica y los modos de "hacer política" inherentes a ellas.

Como tema progresista, la posición y el tratamiento que se adopten frente a ellos depende de la interpretación que se privilegie.

Se puede partir de la premisa de que, desde un punto de vista progresista, la evaluación de estos fenómenos es casi necesariamente negativa. Ellos están en contradicción con los ideales de participación ciudadana republicana y de autogobierno y 
autodeterminación de la sociedad nacional propios de estas visiones. Por consiguiente, lo que podría llamarse repolitización debería ocupar un lugar prioritario en la agenda. No obstante, el sentido que quepa atribuir a esa repolitización encierra también ambigüedades notables. Ese sentido varía, y como se señaló, la variación se relaciona con la perspectiva explicativa que se adopte.

Desde la primera interpretación, repolitizar implicaría identificar ofertas directamente orientadas a la superación de los déficits de integración socioeconómica, ofertas que hagan plausible la superioridad de estrategias políticas colectivas versus estrategias individuales o de pequeños grupos. De otra manera, repolitizar significaría impulsar formas más bien clásicas de movilización sociopolítica.

Pero si se acoge la segunda interpretación, repolitizar tendría que significar identificar nuevos escenarios para el quehacer político, escenarios que conlleven roles y guiones igualmente nuevos, más atractivos y motivantes que los tradicionales, que estarían en proceso de tornarse obsoletos o anacrónicos en el seno de un conjunto de procesos de cambio cuya operación está a la vista.

Esta disyuntiva, usualmente no hecha explícita, atraviesa inadvertida muchas de las discusiones, polémicas y enfrentamientos coyunturales de hoy en día. Es una cuestión abierta, a la que no es fácil responder, y ciertamente la respuesta que se le dé, en la puesta en obra de una opción por uno de los términos de la disyuntiva, proyectará una larga sombra en la historia posterior.

\section{Pluralismo versus libertades clásicas}

Una penúltima cuestión que hay que destacar la define la oposición pluralismo versus homegeneidad social, y ello en relación con el valor de la libertad. Las corrientes progresistas contemporáneas se definen como pluralistas y el objetivo de una sociedad más pluralista parece ser aceptado sin mayor problema en sus agendas. Pero nuevamente las cosas no son tan claras como sería deseable que lo fuesen.

En términos de la realidad socio y político-cultural contemporánea, pluralismo es algo distinto de la vigencia progresivamente más amplia de los derechos que operacionalizan el ideal de libertad. Esa causa, la de la libertad, es común a progresistas, liberales y conservadores libertarios. Y paradójicamente lo que la noción de pluralismo pone en juego es más bien la posible existencia de límites al ejercicio de la libertad, pero en términos mucho más societales que individuales.

En ese sentido, la cuestión del pluralismo está más cercana a la cuestión de la tolerancia, tal como se planteó en el área de civilización protestante: tolerancia entre distintos credos implica no-agresión, dejar existir, reconocimiento recíproco en términos de diversas iglesias u organizaciones que expresan modalidades distintas y aún adversariales de una misma fe. Si bien la tolerancia involucra una dimensión de reconocimiento y vigencia de derechos individuales, lo crucial en ella es la dimensión societal. 
Las demandas contemporáneas por pluralismo poseen esa misma connotación societal, pero con un sentido de mayor radicalidad. De lo que se trata es de un reconocimiento recíproco entre formas de vida muy diferentes, aún con un potencial importante de adversariedad que tiende a emerger en la interacción cotidiana entre ellas, interacción que está sujeta a la restricción de no poder ignorarse mutuamente en cuanto están incluidas en una misma sociedad nacional. Las implicancias de un creciente pluralismo en términos de exigencias prácticas de comportamiento no puede traducirse en un ignorarse recíprocamente, un dejar hacer en el ámbito de cada cual, porque las diversas formas de vida están obligadas ya no a coexistir en el seno de una misma sociedad nacional que las incluye, sino a convivir en el contexto de esa sociedad, y esa convivencia es la que genera una estructura de oportunidades para la adversariedad.

Al hablar de posibles límites al ejercicio de la libertad, o al menos de ciertas libertades, en relación con el compromiso de hacer vigente o efectivo el pluralismo, la referencia es precisamente a esa potencial adversariedad entre las formas de vida que conviven en una misma sociedad nacional. Por ejemplo, el ejercicio pleno de la libertad de expresión, manifestando públicamente posiciones abierta e intensamente críticas de una determinada forma de vida, pueden ser disfuncionales al objetivo de preservar una sociedad plural. No otra es la fundamentación de la oposición "políticamente correcto versus políticamente incorrecto" cuando esa oposición está referida a una forma de vida, sus rasgos de comportamiento que le son típicos o señales externas igualmente típicas. El pluralismo exige respetarlas, y ese respeto implica el deber de silenciar opiniones, sentimientos y juicios que agreden la forma de vida en cuestión.

Así, el pluralismo puede significar costos importantes, que hay que estar dispuestos a pagar como sociedad para que sea efectivo. El dilema es cuánto se está dispuesto a renunciar en términos de universalidad en pos de particularismo, y cuánto de particularismo debe sacrificarse en pos de universalidad, lo que implica al menos la mantención de un nivel mínimo crítico de homogeneidad. Esos son los términos de un debate, que con frecuencia se asume con un facilismo poco responsable, y que conducen lógicamente a reforzar -a "enriquecer" aún más, podría decirse- el campo de tensiones en que se inserta el progresismo.

\section{El asalto a la racionalidad crítica}

Finalmente, hay una cuestión que no se puede dejar de mencionar: la que resulta de lo que se podría llamar la "crisis de la racionalidad crítica".

Una de las tendencias de la nueva modernidad capitalista es absorber la racionalidad crítica -obviamente, ejercida sobre lo social, ya que no tiene sentido criticar lo natural- en racionalidad científico-técnica, "pura" o aplicada.

Asociado a ello, la crítica se orienta crecientemente a plasmarse no racionalmente: "arracionalmente" o irracionalmente. Lo que tiende a predominar en términos de crítica son modalidades de expresividad estética, expresividad puramente afectiva, enjuiciamiento 
moral irreflexivo, y el quehacer político o las formas de "hacer política" reflejan precisamente ésto, ciertamente en asociación con modalidades de racionalidad científicotécnica aplicadas, como el marketing o mercadeo.

Entre otras cosas, esto clausura la posibilidad de que emerjan y se exploren visiones o proyectos de futuro, que busquen validarse no sólo por su efectividad política coyuntural o situacional, sino a la vez analítica, empírica y reflexivamente, aspirando en consecuencia a desplegarse en tiempos largos.

De allí la pregunta: ¿es lo postmoderno un rasgo esencial ya permanente de la nueva modernidad capitalista, o sólo una posibilidad superable? Otro de los términos del debate, cuya importancia el progresismo pasa por alto con frecuencia. 